\title{
Short communication Why patient recorded outcomes should be mandatory in and outside clinical trials to guide management of patients with metastatic breast cancer
}

\author{
Lesley Fallowfield
}

CRUK Sussex Psychosocial Oncology Group, Brighton \& Sussex Medical School, University of Sussex, Falmer, BN1 5JN, UK

Corresponding author: Lesley Fallowfield, L.J.Fallowfield@sussex.ac.uk

Published: 20 December 2007

This article is online at http://breast-cancer-research.com/content/9/S2/S7 (c) 2007 BioMed Central Ltd
Breast Cancer Research 2007, 9(Suppl 2):S7 (doi:10.1186/bcr1805)

physicians. Observation of oncologists working in busy clinics shows that the manner in which adverse events and side effects are recorded is not especially reliable. For example, even within the relatively tightly controlled setting of a clinical trial, the sensitivity and specificity of the detection of common chemotherapy side effects are unacceptably low [15]. Several other studies have examined the lack of congruence between patient and physician recording of side effects that have an impact on QoL; many are either underestimated or unrecognized altogether by clinicians [16-18]. This is serious because accurate recognition of bothersome side effects could influence the initiation, continuation, change, or termination of therapy, and may prompt timely instigation of other supportive and ameliorative interventions. Information from patient self-report questionnaires may provide a different viewpoint about tolerability and toxicity that is not always recognized as important by health care professionals, and accumulation and discussion of such information enables patients to make more informed choices regarding their treatment options. Some of the side-effects of treatment, especially vasomotor complaints, affect adherence to treatment even in women with advanced disease [19].

Despite the evidence supporting formal data collection, patient self-report assessments still fail to influence management decisions as much as traditional outcomes, such as tumour markers or other objective measures. This is curious given accumulating data from studies in metastatic melanoma, colorectal, lung and breast cancer that demonstrate the predictive and prognostic value of baseline QoL measurement [20]. This predictive information is independent of that derived from other orthodox measures [21]. Studies in patients with advanced breast cancer indicated that regular assessment revealed a decline in QoL scores when disease ceased to respond to chemotherapy, and again this occurred before any indications from other objective measures [22]. 
Collection of data from formal QoL instruments broadens the parameters of benefit beyond response and survival, and allows a more accurate determination of the supportive and ameliorative interventions that patients with $\mathrm{MBC}$ require. The challenge of how to convince clinicians of its value remains. Many worry about the practical difficulties of administering, scoring and interpreting QoL questionnaires, although some researchers have achieved this successfully in their own routine oncology practice [23]. Recently published recommendations from the European School of Oncology have stated the importance of thorough QoL assessment in MBC [24].

It is interesting that the practical and financial burdens associated with measuring tumour markers, despite the questionable utility of these in $\mathrm{MBC}$, do not appear to have been subjected to the scepticism and scrutiny that is reserved for formal measurement of QoL variables.

\section{Acknowledgement}

This article has been published as part of Breast Cancer Research Volume 9 Supplement 2, 2007: Controversies in Breast Cancer. The full contents of the supplement are available online at http://breastcancer-research.com/supplements/9/S2.

\section{References}

1. Kissane DW, Grabsch B, Love A, Clarke DM, Bloch S, Smith GC: Psychiatric disorder in women with early stage and advanced breast cancer: a comparative analysis. Aust $N$ Z J Psychiatry 2004, 38:320-326.

2. Turner J, Kelly B, Swanson C, Allison R, Wetzig N: Psychosocial impact of newly diagnosed advanced breast cancer. Psychooncology 2005, 14:396-407.

3. Passik SD, Dugan W, McDonald MV, Rosenfeld B, Theobald DE, Edgerton S: Oncologists' recognition of depression in their patients with cancer. J Clin Oncol 1998, 16:1594-1600.

4. Fallowfield L, Ratcliffe D, Jenkins V, Saul J: Psychiatric morbidity and its recognition by doctors in patients with cancer. $\mathrm{Br} J$ Cancer 2001, 84:1011-1015.

5. Devine EC, Westlake SK: The effects of psychoeducational care provided to adults with cancer: meta-analysis of 116 studies. Oncol Nurs Forum 1995, 22:1369-1381.

6. Sheard T, Maguire P: The effect of psychological interventions on anxiety and depression in cancer patients: results of two meta-analyses. Br J Cancer 1999, 80:1770-1780.

7. Newell SA, Sanson-Fisher RW, Savolainen NJ: Systematic review of psychological therapies for cancer patients: overview and recommendations for future research. $J$ Natl Cancer Inst 2002, 94:558-584.

8. Rehse B, Pukrop R: Effects of psychosocial interventions on quality of life in adult cancer patients: meta analysis of 37 published controlled outcome studies. Patient Educ Couns 2003, 50:179-86.
9. Meyer TJ, Mark MM: Effects of psychosocial interventions with adult cancer patients: a meta-analysis of randomized experiments. Health Psychol 1995, 14:101-108.

10. Goodwin PJ: Support groups in advanced breast cancer. Cancer 2005, 104(suppl):2596-2601.

11. Classen C, Butler LD, Koopman C, Miller E, DiMiceli S, GieseDavis J, Fobair P, Carlson RW, Kraemer HC, Spiegel D: Supportive-expressive group therapy and distress in patients with metastatic breast cancer: a randomized clinical intervention trial. Arch Gen Psychiatry 2001, 58:494-501.

12. Edelman $S$, Bell $D R$, Kidman $A D$ : $A$ group cognitive behaviour therapy programme with metastatic breast cancer patients. Psychooncology 1999, 8:295-305.

13. National Institute for Clinical Excellence: National Institute for Clinical Excellence; Improving supportive and palliative care for adults with cancer. London, UK: National Institute for Clinical Excellence; 2004

14. Turner J, Zapart S, Pedersen K, Rankin N, Luxford K, Fletcher J; National Breast Cancer Centre, Sydney, Australia; National Cancer Control Initiative, Melbourne, Australia: Clinical practice guidelines for the psychosocial care of adults with cancer. Psychooncology 2005, 14:159-173.

15. Fromme EK, Eilers KM, Mori M, Hsieh YC, Beer TM: How accurate is clinician reporting of chemotherapy adverse effects? A comparison with patient-reported symptoms from the Quality-of-Life Questionnaire C30. J Clin Oncol 2004, 22: 3485-3490.

16. Fellowes D, Fallowfield $\amalg$, Saunders CM, Houghton J: Tolerability of hormone therapies for breast cancer: how informative are documented symptom profiles in medical notes for 'well-tolerated' treatments? Breast Cancer Res Treat 2001, 66:73-81.

17. Coombes RC, Bliss J, Hall E, Gibson L, Fallowfield L, Massimini $\mathrm{G}$, for the Intergroup Exemestane Study: Under-reporting of symptoms in patients with early breast cancer who have received tamoxifen treatment for $2-3$ years [abstract]. Proc Am Soc Clin Oncol 2003, 22:48.

18. Savage C, Pater JL, Tu D, Norris B: He said/she said: how much agreement is there on symptoms between common toxicity criteria and quality of life? [abstract]. Proc Am Soc Clin Oncol 2002, 22:1540.

19. Cox AC, Fallowfield $U$, Jenkins VA: Communication and informed consent in phase 1 trials: a review of the literature. Support Care Cancer 2006, 14:303-309.

20. Fallowfield L: Quality of life: a new perspective for cancer patients. Nat Rev Cancer 2002, 2:873-879.

21. Coates A, Poezsolt F, Osoba D: Quality of life in oncology practice: prognostic value of EORTC QLQ-C30 scores in patients with advanced malignancy. Eur J Cancer 1997, 33:1025-1030.

22. Fraser SC, Ramirez AJ, Ebbs SR, Fallowfield LJ, Dobbs $\mathrm{HJ}$, Richards MA, Bates T, Baum M: A daily diary for quality of life measurement in advanced breast cancer trials. $\mathrm{Br} J$ Cancer 1993, 67:34-36.

23. Velikova G, Booth L, Smith AB, Brown PM, Lynch P, Brown JM, Selby $P J$ : Measuring quality of life in routine oncology practice improves communication and patient well-being: a randomized controlled trial. J Clin Oncol 2004, 22:714-724.

24. Cardoso F, Winer EP, Fallowfield L, Namer M, Pagani O, Rodenhuis S, Senkus-Konefka S, Wardley A, Costa A: Guidelines, metastatic breast cancer. Recommendations from the European School of Oncology- MBC Task Force. The Breast 2007, 16:9-10. 